\title{
ACADEMIC GOALS ORIENTATION QUESTIONNAIRE FOR COLOMBIAN NURSING STUDENTS: VALIDITY AND RELIABILITY STUDY
}

\section{ABSTRACT}

Background: Academic motivation guides students toward the achievement of academic objectives and influences their learning. However, there is little research on this subject in nursing education, and validated instruments are not available in Latin America.

Objective: To determine the validity and reliability of the Academic Goals Orientation Questionnaire in Colombian nursing students.

Design: Cross-sectional psychometric study developed in the second semester of 2016.

Settings and participants: Undergraduate students in nursing at the National University of Colombia $(\mathrm{n}=323)$

Methods: The Academic Goals Orientation Questionnaire was administered electronically. In addition, the variables of age, sex and academic year were collected. An analysis of construct validity was carried out by exploratory and confirmatory factor analysis. The reliability of the questionnaire was studied with Cronbach's alpha.

Results: The exploratory factor analysis revealed the presence of four factors that explain $53.4 \%$ of the total variance and that correspond to the dimensions of the original instrument. The overall reliability was $\alpha=0.714$. The confirmatory factor analysis verified a good fit of the model $\left(\chi^{2}=128, p=0.024\right)($ SRMR $=0.0471)(\mathrm{RMSEA}=0.03, \mathrm{IC} 95 \%=0.011-0.044)$ $(\mathrm{CFI}=0.972)$. The learning or task goal obtained the highest average score $(\mathrm{m}=4.67,95 \%$ $\mathrm{CI}=4,629-4,712)$, and the Work avoidance goal was the worst rated $(\mathrm{m}=2,126,95 \% \mathrm{CI}=$ $2,055-2,198)$ by the students.

Conclusion: The Academic Goal Orientation Questionnaire has an adequate validity and reliability in the Colombian context that allows it to be applied in nursing students. However, it is recommended to expand the study with larger samples and other countries in the same context.

Keywords: Nursing education; nursing students; academic performance; academic achievement 


\section{$\underline{\text { INTRODUCTION }}$}

Academic motivation is a set of processes involved in the activation, direction and persistence of the behaviour that guides students toward the achievement of certain academic objectives (Pekrun et al., 2006). Moreover, the orientation of achievement objectives is defined as a person's motivating purpose to participate in a specific task (Sparfeldt et al., 2015) and is considered a cognitive representation of what a person wants to achieve (Pintrich et al., 2003). The type of orientation can influence the way a person works to accomplish results, goals and academic achievements (Lee et al., 2010).

The care of people and communities requires nursing professionals with a high level of competence and training. However, the orientation of the students' academic goals may affect their acquisition of competencies and learning outcomes. Knowing the orientation of the academic goals of nursing students is important for teachers and helps in making decisions about the selection and admission of students and academic guidance programs as well as in the design of the curriculum and educational interventions (Misch, 2002; Barkur et al., 2013; Filiz et al., 2018). However, in the literature there is little research on nursing education and the orientation of academic goals, and none has been developed in Latin America. In fact, no validated instruments are available to study the orientation of academic goals in this context.

\section{$\underline{\text { BACKGROUND }}$}

Academic goals define the content and direction of a person's motivation for academic success or failure (Sparfeldt et al., 2015), there being four types of goals described by Skaalvik (1997): (i) Learning or task goals; (ii) Ego self-enhancement goals; (iii) Ego selffrustration goals; and (iii) Work avoidance goals.

On one hand, Learning or task goals focus on the development and mastery of competencies. The student with this type of goals focuses on intrinsic stimuli and seeks to assimilate knowledge and acquire skills and a real understanding of the issues (Senko et al., 2013). On the other hand, Ego-oriented goals are social in nature through which the student seeks to satisfy extrinsic needs through academic performance. These goals are linked to Ego self-enhancement (seeking favourable results) and Ego self-frustration (having a defensive 
attitude and seeking to avoid frustration and an unfavourable image) (Skaalvik, 1997). Both types of academic orientation have social components. That is, students seek social, academic or family recognition, either to be better than their peers or to not present mediocre results rather than to satisfy their knowledge needs (Zong et al., 2017). The fourth type of academic goal orientation is based on the avoidance of work. The student avoids learning situations by using common behaviours such as making minimal effort and avoiding complex tasks (Deemer et al., 2010).

In nursing studies, the literature relates personal factors such as care of children, cultural differences or ignorance of what nursing is and other factors such as the intensity of studies, clinical practices or the lack of counselling programs with academic burnout (ValeroChillerón et al., 2019), the abandonment of studies or the success and fulfilment of academic goals (Chan et al., 2019, Mooring, 2106). However, there are few studies that include the type of academic goal orientation of students of health sciences, and specifically of nursing, as a relevant factor that may influence these and other aspects.

Barkur et al. (2013) studied the correlation between academic goal orientation and academic performance in a sample of 244 medical students, concluding that lower performing students had a work avoidance orientation in comparison with the students who obtained better grades. These results are similar to those obtained in nursing students by March and Robinson (2015) and Palos (2018). On the other hand, Filiz et al. (2018) and Navea Martín (2012) affirmed that the orientation of the Learning goal is the predominant one among nursing students, and Kim et al. (2016) concluded that the type of orientation toward the Ego self-frustration goal is related to the presence of burnout, less critical thinking skills (Martyn et al., 2014) and a greater risk of concealment of errors in clinical practice (Dunn, 2014).

In the literature review, no Latin American studies were found on this topic, probably due to the lack of validated instruments for measuring students' orientation to academic goals. In this sense, the Academic Goals Orientation Questionnaire was developed and validated by Skaalvik (1997). Subsequently, this questionnaire was validated by Navea Martín (2012) in the Spanish context in a sample of 103 nursing students, although their psychometric properties are not known in the Latin American context. In this way, the objective of this study was to determine the validity and reliability of the Academic Goal 
Orientation Questionnaire (Skaalvik, 1997), adapted to Spanish by Navea Martín (2012), in Colombian nursing students.

\section{$\underline{\text { METHODOLOGY }}$}

\section{$\underline{\text { Design }}$}

This cross-sectional psychometric instrumental study determined the reliability and validity of the Academic Goals Orientation Questionnaire (Skaalvik, 1997) in Colombian nursing students, adapted and validated in Spain by Navea Martín (2012). The study was carried out in the second semester of 2016.

\section{Population and sample}

The population consisted of 500 students in the nursing degree program at the National University of Colombia. The sample size was established at a minimum of 5-10 individuals per item, which involved at least 80 participants (16 items) (Beaton et al., 2000, Anthoine et al., 2014). Students who did not wish to participate in the study, students in the exchange program and poorly completed questionnaires were excluded.

\section{$\underline{\text { Instrument }}$}

The Academic Goals Orientation Questionnaire has 16 items that raise questions about what guides student learning. The respondent marks the answer that best describes his or her personal situation with a Likert scale of five levels ( $1=$ in total disagreement; 5 = in total agreement). The items are organized in four dimensions, according to the types of academic goal orientation: (i) Learning or task goal (items 1, 5, 9, 16); (ii) Ego selfenhancement goal (items 2, 6, 10, 3); (iii) Ego self-frustration goal (items 4, 7, 11, 14); and (iv) Work avoidance goal (items 3, 8, 12, 15) (Navea Martín, 2012). In addition, the variables of age, sex and academic year were collected.

The reliability of the original scale was adequate, with Cronbach's alphas $(\alpha)$ greater than 0.8 in all dimensions (Learning goal $\alpha=0.81$, Ego self-enhancement goal $\alpha=0.86$, Ego self-frustration goal $\alpha=0.89$, Work avoidance goal $\alpha=0.93$ ) (Skaalvik, 1997). In the Spanish version validated by Navea Martín (2012), the index of validity of total content was 0.72 and the adequate internal consistency, with $\alpha=0.55$ for the Learning goal, $\alpha=0.79$ for the Ego 
self-enhancement goal, $\alpha=0.90$ for the Ego self-frustration goal, and $\alpha=0.69$ for the Work avoidance goal.

\section{$\underline{\text { Procedure for data collection }}$}

An online questionnaire was created in Google Drive and sent by e-mail to all students enrolled in any of the five courses of the nursing degree program at the National University of Colombia. The first part of the questionnaire included the authorization to participate in the study and a box that needed to be checked to continue. The data collection was carried out during the second semester of 2016, and the link was available for a month. Subsequently, the data was exported to SPSS for analysis.

\section{$\underline{\text { Statistical analysis }}$}

A descriptive analysis of the sample and the results of the questionnaire was carried out, according to the nature of the variables. The construct validity was studied with an exploratory factorial analysis (main components with Varimax rotation), previous confirmation of its viability with the Kaiser-Meyer-Olkin test (KMO) and the Bartlett test. In addition, a confirmatory factor analysis was performed. The goodness of fit was studied by means of the chi-square $\left(\chi^{2}\right.$, small scores indicate good fit), standardized mean square residue (SRMR $<0.05$ indicates a good fit), mean square error of approximation (RMSEA $<0.05$ indicates a good adjustment) and comparative adjustment index (CFI $\geq 0.97$ indicates a good fit). The internal consistency of the questionnaire and its dimensions was studied with Cronbach's alpha $(\alpha)$. The statistical analysis was carried out with the SPPS V22 and Jamovi V1.0.0 programs. A level of significance of $p<0.05$ was considered.

\section{Ethical considerations}

The study was approved by an external ethics committee of the National University of Colombia (Act 15 of 07/16/2016 of Agenf.org). No personal data was collected that would allow the identification of the students, and participation was completely voluntary and anonymous. The study complied with current legislation in Colombia on the protection of personal data, and the ethical principles of the Declaration of Helsinki were respected at all times (beneficence, non-maleficence, autonomy and justice).

\section{$\underline{\text { RESULTS }}$}




\section{Description of the sample}

Participating in the study were 332 nursing students, with a response rate of $66.4 \%$. However, three participants were discarded as exchange students, and six were discarded because they did not complete at least half of the questionnaire. Thus, the final sample of participants was 323 nursing students. The mean age of the sample was 20.86 (IC95\% = 20.47-21.25) years; $65 \%(n=213)$ were women and the rest were men. The participants included 38.5\% $(\mathrm{n}=126)$ first-year students, 9.8\% $(\mathrm{n}=32)$ second-year students, $13.8 \%(\mathrm{n}=$ 45) third-year students, $21.1 \%(n=69)$ fourth-year students and 16.2\% $(n=53)$ fifth-year students. Regarding the questionnaire, the learning or task goal obtained the highest average score $(\mathrm{m}=4.67,95 \% \mathrm{CI}=4.629-4.712)$, and the Work avoidance goal had the lowest average score $(\mathrm{m}=2.126,95 \% \mathrm{CI}=2.055-2.198)$. Table 1 shows the descriptive results of the questionnaire.

Table 1. Descriptive results of the Academic Goals Orientation Questionnaire

Items and dimensions $\quad$ m $(95 \% \mathrm{CI})$

Ego self-frustration goal

$2.501(2.388-2.615)$

4.- When I answer questions that are asked in class, I am worried about what my classmates are going to think.

$2,697(2,564-2.83)$

7.- When I participate in an activity, I am worried about what my

classmates may be thinking about me.

$2,492(2,342-2,641)$

11.- In class, I worry about being ridiculed.

14.- When I answer incorrectly in class, what worries me the most is what my classmates think of me.

\begin{tabular}{|c|c|}
\hline Ego self-enhancement goal & $3.048(2.952-3.145)$ \\
\hline 13.- In studies, I always try to do better than other students. & $3.204(3.076-3.333)$ \\
\hline 6.- I try to get higher grades than other students. & $3.107(2.972-3.241)$ \\
\hline $\begin{array}{l}\text { 2.- Succeeding in these studies is doing homework better than other } \\
\text { students. }\end{array}$ & $2.749(2.626-2,872)$ \\
\hline $\begin{array}{l}\text { 10.- It is important for me to know how to do task that other } \\
\text { classmates do not know. }\end{array}$ & $3.134(3.001-3.267)$ \\
\hline Work avoidancegoal & $2.126(2.055-2.198)$ \\
\hline 8.- I prefer the subjects in which I do not have to work. & $2.021(1.91-2.132)$ \\
\hline 15.- I try to avoid difficult tasks or subjects. & $2.033(1.929-2.138)$ \\
\hline
\end{tabular}


12.- In class, I prefer to do as little as possible.

$1.819(1.708-1.931)$

3.- I do not want work to be done at home.

\section{Learning or task goal}

4.67 ( 4.629-4.712)

16.- In class, I like to learn interesting things,

$4.81(4.751-4.869)$

1.- It is important for me to learn new things,

9.- It is important for me to learn to solve the problems that are proposed.

\section{$\underline{\text { Psychometric properties }}$}

The results of the Kaiser-Meyer-Olkin test $(\mathrm{KMO}=0.777)$ and the Barlett test (Chi: $1168 ; p<0.001)$ verified the viability of the exploratory factor analysis. The method of principal components and Varimax rotation was used, returning a structure of four factorial axes that explain $53.498 \%$ of the total variance. The first factor (Ego self-frustration goal) explained $17.182 \%$ of the variance (items $4,7,11,14$ ). The second factor coincided with the Ego self- enhancement goal and explained $14.486 \%$ of the total variance (items $2,6,10,3$ ). The third factor explained $11.148 \%$ of the variance, formed by items $3,8,12,15$, and it corresponded with the Work avoidance goal. The fourth factor corresponded to the Learning goal dimension and explained $10.682 \%$ of the total variance (items $1,5,9,16$ ). The structure of the questionnaire, with correlation values higher than 0.5 in all cases, coincided with the original structure, and the Varimax rotation managed to converge in five iterations (Table 2).

The results of Cronbach's $\alpha$ coefficient confirmed an adequate internal consistency for the questionnaire $(\alpha=0.714)$ and its dimensions (Ego self-frustration goal $\alpha=0.838$; Ego self-enhancement goal $\alpha=0.733$; Work avoidance goal $\alpha=0.535$; Learning goal $\alpha=0.508$ ). Table 2 shows the matrix of rotated components, the anti-image correlations and the results of internal consistency by dimensions and how it affects $\alpha$ if each item is eliminated.

Table 2. Matrix of rotated components and analysis of internal consistency.

\begin{tabular}{lllllll}
\hline \multirow{2}{*}{ Dimensions and items } & \multicolumn{5}{c}{ Factors } \\
\cline { 2 - 4 } Anti-image & $\alpha$
\end{tabular}

Ego self-frustration goal. 


\begin{tabular}{|c|c|c|c|c|c|c|}
\hline Item 4 & .839 & .097 & .012 & -.031 & .774 & .784 \\
\hline Item 7 & .815 & .118 & .170 & -.111 & .843 & .813 \\
\hline Item 11 & .789 & .139 & .128 & -.013 & .849 & .797 \\
\hline Item 14 & .777 & .112 & .059 & -.085 & .820 & .785 \\
\hline \multicolumn{6}{|c|}{ Ego self-enhancement goal. } & .733 \\
\hline Item 13 & .158 & .796 & -.094 & -.019 & .748 & .619 \\
\hline Item 6 & .150 & .779 & -.002 & -.054 & .737 & .633 \\
\hline Item 2 & .022 & .711 & .051 & -.104 & .756 & .698 \\
\hline Item 10 & .106 & .632 & .122 & .037 & .861 & .731 \\
\hline Work avoidance goal. & & & & & & .535 \\
\hline Item 8 & .067 & .094 & .750 & -.054 & .633 & .382 \\
\hline Item 15 & .090 & .032 & .713 & -.074 & .722 & .398 \\
\hline Item 12 & .209 & .080 & .533 & -.059 & .820 & .495 \\
\hline Item 3 & -.24 & -.086 & .512 & -.053 & .653 & .562 \\
\hline Learning or task goal. & & & & & & .508 \\
\hline Item 16 & -.081 & -.111 & -.094 & .689 & .733 & .386 \\
\hline Item 1 & -.039 & -.121 & .126 & .686 & .678 & .446 \\
\hline Item & -.150 & -.044 & -.164 & 9.670 & .728 & .378 \\
\hline Item 5 & .082 & .255 & -.201 & .514 & .703 & .544 \\
\hline
\end{tabular}

Figure 1 shows the path diagram after the confirmatory factor analysis, including the variances, covariance and factor loads of the items and dimensions. The result of $\chi^{2}(128, p=$ 0.024), SRMR (0.0471), RMSEA (0.03, IC95\% = 0.011-0.044) and CFI (0.972) confirmed a good fit between the model structure and data.

\section{Figure 1. Path diagram}




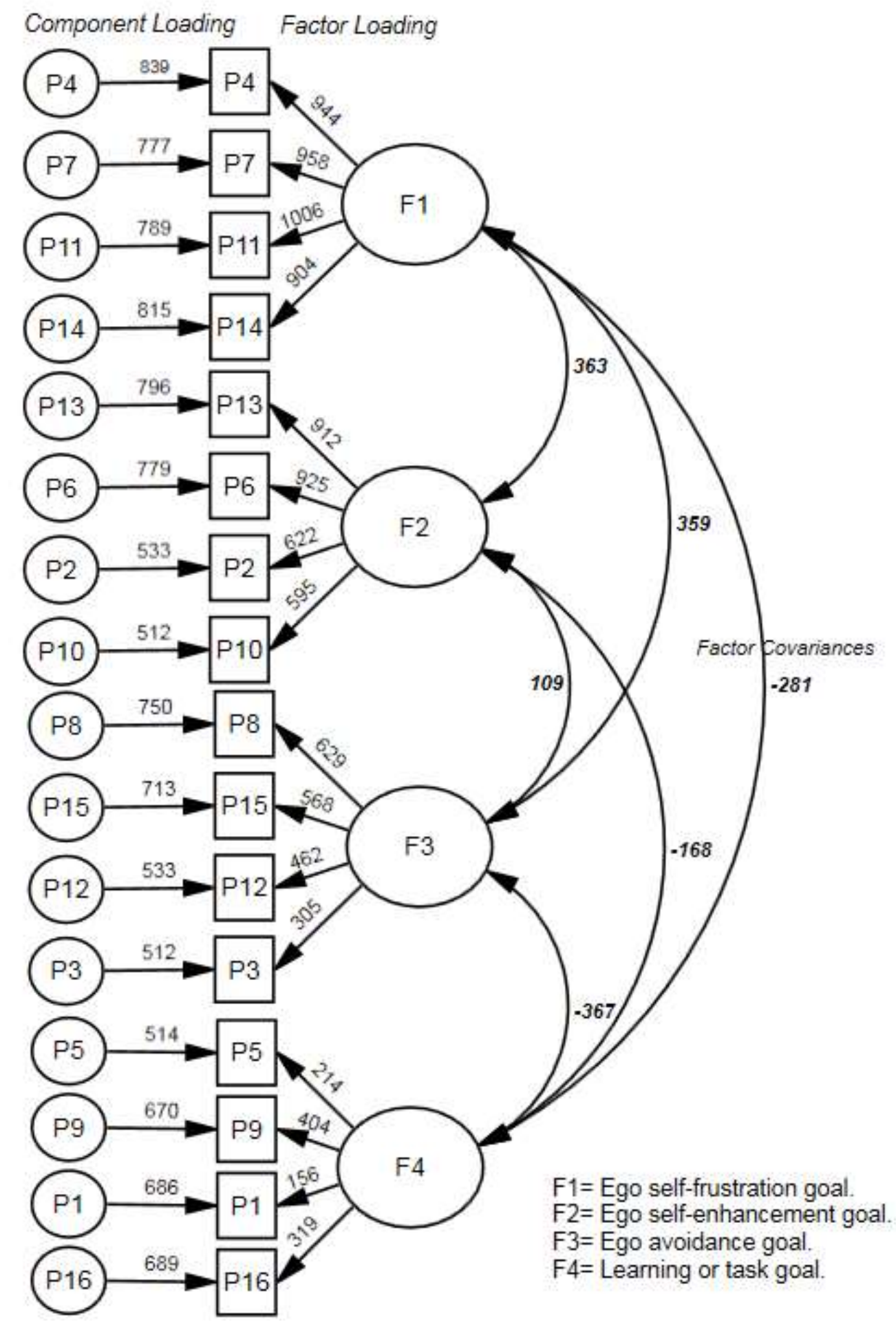

\section{DISCUSSION}

The results obtained confirm that the Academic Goals Orientation Questionnaire is valid and reliable enough to be used in Colombian nursing students. These results coincide with the original version developed by Skaalvic (1997) and with the validation of the questionnaire carried out in Spain by Navea Martín (2012). In general, the exploratory factor 
analysis identified four types of academic goal orientation, with factor loads greater than 0.5 and anti-image correlations greater than 0.6 in all items. However, the results of Cronbach's alpha showed an internal consistency that can be considered low in the learning or task goal $(\alpha=0.508)$ and the Work avoidance goal $(\alpha=0.535)$, although they were similar to those obtained by Navea Martín (2012). On the other hand, Cronbach's alpha value is affected by factors such as systematic error, the deviation of unidimensionality (Shevlin et al., 2000) or the presence of atypical cases (Liu and Zumbo, 2007), and values lower than 0.7 can be considered adequate enough, although with caution (Ponterotto and Ruckdeschel, 2007). It is possible that a previous analysis of face validity and content in the Colombian context would have improved the results of internal consistency. Otherwise, the results of the confirmatory factor analysis verified a good adjustment of the questionnaire.

On one hand, Elliot and McGregor (2001) developed and validated a similar questionnaire in psychology students. This questionnaire, formed by the same dimensions and with three items in each dimension, was used by March and Robinson (2015) in 151 nursing students in the United States, although the authors did not report their psychometric properties in the sample studied. Filiz et al. (2018) used a version adapted in Turkey by Akin (2006), obtaining an adequate internal consistency $(\alpha=0.82)$ in a sample of 226 nursing students, and Palos (2018) reported an $\alpha=0.85$ in a sample of 120 Romanian nursing students. On the other hand, Kim et al. (2016) used an earlier version of the same questionnaire (Elliot \& Church, 1997) consisting of six items and three types of academic goal orientation (did not include the Work avoidance goal), although the authors did not report their psychometric properties. In our study, it was decided to use the questionnaire developed and validated by Skaalvic (1997) because it had a version validated in Spanish by Navea Martín (2012).

The orientation of the learning or task goal obtained the highest score in this study, and the orientation of the ego avoidance goal was the worst valued by the students. These results coincide with those of Navea Martín (2012), March and Robinson (2015), Filiz et al. (2018) and Palos (2018) and can be interpreted so that nursing students look for intrinsic motivations that guide them toward the acquisition of knowledge and the development of competencies (Senko et al., 2013 ). It is possible that these results are related to the vocational nature of nursing, although it is also possible that when these types of questionnaires are completed, the students reflect the knowledge in themselves as their 
purpose, even if their motivation is really another, or a combination of several orientations of achievement toward academic goals (Navea Martín (2012).

These results should be considered with caution because the study was conducted in a single university and facial and content validity was not studied. However, the sample size was considered adequate for the purpose of the study and confirmatory factor analysis verified a good adjustment of the questionnaire. Despite this limitation, the results are considered relevant because they provide a validated version of the Academic Goals Orientation Questionnaire in Colombia and allow the development of new research focused on the strategies used by students in their learning, the development of programs of academic orientation and curriculum design or educational interventions.

\section{CONCLUSIONS}

The Academic Goal Orientation Questionnaire has an adequate validity and reliability in the Colombian context that allows it to be applied in nursing students. However, it is recommended to extend the study to other countries of the Latin American context and with broader samples as well as to deepen the face and content validity to improve its internal consistency. However, the study of the academic goals of nursing students can facilitate the identification of their academic orientation and therefore can become a support tool for teachers when selecting students and adapting the contents of the curricular program accordingly.

\section{$\underline{\text { REFERENCES }}$}

Akın A. 2X2 Achievement Goal Orientations Scale. Sakarya University Journal of Educational Faculty, 2006, 12: 1-13.

Anthoine E, Moret L, Regnault A, Sébille V, Hardouin JB (2014). Sample size used to validate a scale: a review of publications on newly-developed patient reported outcomes measures. Health and quality of life outcomes, 12, 176. DOI: 10.1186/s12955-014-01762

Barkur RR, Govindan S, Kamath A (2013). Correlation between academic achievement goal orientation and the performance of Malaysian students in an Indian medical school. Education for Health, 26 (2), 98. DOI: 10.4103/1357-6283.120701. 
Beaton DE, Bombardier C, Guillemin F, Ferraz MB (2000). Guidelines for the process of cross-cultural adaptation of self-report measures. Spine, 25 (24), 3186-3191. DOI: 10.1097/00007632-200012150-00014

Chan ZCY, Chan HY, Chow HJC, Choy SN, Ng KY, Wong KY, Yu PK (2019). Academic advising in undergraduate education: A systematic review. Nurse Educ Today, 75, 58-74. DOI: 10.1016/j.nedt.2019.01.009

Deemer ED, Carter AP, Lobrano MT (2010). Extending the $2 \times 2$ Achievement Goal Framework: Development of a Measure of Scientific Achievement Goals. Journal of Career Assessment, 18 (4), 376-392. DOI: 10.1177/1069072710374575.

Dunn KE (2014). Insight into error hiding: Exploration of nursing students' achievement goal orientations. Journal of Nursing Education, 53 (2), 93-96. DOI: 10.3928/0148483420140122-02

Elliot AJ and Church MA (1997). A hierarchical models of approach to motivation and avoidance achievement motivation. J Pers Soc Psychol., 72, 218-232. DOI: 10.1037/0022-3514.72.1.218

Elliot AJ \& McGregor HA (2001). A 2x2 achievement goal framework. Journal of Personality and Social Pathology, 80, 501-519. DOI: 10.1037 / 0022-3514.80.3.501

Filiz NY, Erol F, Basaran H, Tanrikulu F, Dikmen Y (2018). Investigation of Achievement Orientation of Nursing and Midwifery Students. Current health sciences journal, 44 (2), 176.

Kim EY, Lim EJ, Noh JH (2016). Academic Stress, Major Satisfaction, and Academic Achievement according to Type of Achievement Goal Orientation in Nursing Students. International Information Institute (Tokyo). Information, 19 (10A), 4557-4562. Last accesses June $2019 . \quad$ URL: https://search.proquest.com/docview/1888928992/fulltextPDF/6612415A5D14E54PQ/1? accountid=15297

Lee JQ, McInerney DM, Liem GAD, Ortiga YP (2010). The relationship between future goals and achievement goal orientations: An intrinsic-extrinsic motivation perspective. $\begin{array}{lllll}\text { Contemporary } & \text { Educational } & \text { Psychology, } 35 & \text { (4), 264-279. DOI: }\end{array}$ 10.1016/j.cedpsych.2010.04.004

Liu Y and Zumbo BD (2007). The Impact of Outliers on Cronbach's Coefficient Alpha Estimate of Reliability: Visual Analogue Scales. Educational and Psychological Measurement, 67 (4), 620-634. DOI: 10.1177 / 0013164406296976 
March AL, Robinson C (2015). Assessment of high-stakes testing, hopeful thinking, and goal orientation among baccalaureate nursing students. International journal of nursing education scholarship, 12 (1), 123-129. DOI: 10.1515 / ijnes-2014-0075

Martyn J, Terwijn R, Kek MY, Huijser H (2014). Exploring the Relationships between Teaching, Approaches to Learning and Critical Thinking in a Problem-Based Learning Foundation Nursing Course. Nurse Educ Today 34 (5), 829-835. DOI: 10.1016/j. nedt.2013.04.023

Misch DA (2002). Andragogy and medical education: Are medical students internally motivated to learn? Adv Health Sci Educ Theory Pract, 7 (2), 153-60. DOI: 10.1023/A:1015790318032

Mooring QE (2016). Recruitment, advising, and retention programs-Challenges and solutions to the international problem of poor nursing student retention: A narrative literature review. Nurse Educ Today, 40, 204-208. DOI: 10.1016/j.nedt.2016.03.003

Navea Martín A (2012). A Study on the Academic Goals of University Nursing Students. Psicol Educ [Internet]. 18: 83-9. Last accessed June 2019. URL: http://journals.copmadrid.org/psed/archivos/ed2012v18n1a8.pdf

Sticks R (2018). Exploring the impact of achievement goals orientation and study engagement on nursing students' approaches to learning. Educational Studies, 1-16. DOI: $10.1080 / 03055698.2018 .1555454$

Palos R (2018). Exploring the impact of achievement goals orientation and study engagement on nursing students' approaches to learning. Educational Studies, 1-16. DOI: $10.1080 / 03055698.2018 .1555454$

Pekrun R, Elliot AJ, Maier MA (2006). Achievement goals and discrete achievement emotions: A theoretical model and prospective test. J Educ Psuchol, 98 (3), 583-597. DOI: $10.1037 / 0022-0663.98 .3 .583$

Pintrich PR, Conley AM, Kempler TM (2003). Current Issues in Achievement Goal Theory and Research. International Journal of Educational Research 39, 319-337. DOI: 10.1016/j.ijer.2004.06.002

Ponterotto JG, \& Ruckdeschel DE (2007). An overview of coefficient alpha and a reliability matrix for estimating adequacy of internal consistency coefficients with psychological research measures. Perceptual and motor skills, 105 (3), 997-1014. DOI: 10.2466/pms.105.3.997-1014 
Senko C, Hama H, Belmonte K (2013). Achievement Goals, Study Strategies, and Achievement: A Test of the Learning Agenda 'Framework. Learning and Individual Differences, 24, 1-10. DOI: 10.1016/j.lindif.2012.11.003.

Shevlin M, Miles JNV, Davies MNO, Walker S. (2000). Coefficient alpha: a useful indicator of reliability?. Personality and individual differences, 28 (2), 229-237. DOI: 10.1016/S0191-8869 (99) 00093-8

Skaalvik EM (1997). Self-enhancing and self-defeating ego orientation: Relations with task and avoidance orientation, achievement, self-perceptions, and anxiety. J Educ Psychol. 89, 1, 71-81. DOI: $10.1037 / 0022-0663.89 .1 .71 \%$ 0A

Sparfeldt JR, Brunnemann N, Wirthwein L, Buch SR, Schult J, Rost DH. (2015). General versus Specific Achievement Goals: A Re-Examination. Learning and Individual Differences, 43, 170-177. DOI: 10.1016/j.lindif.2015.08.022.

Streiner DL (2003). Starting at the beginning: an introduction to coefficient alpha and internal consistency. J Pers Assess. 80 (1), 99-103. DOI: 10.1207/S15327752JPA8001_18

Valero-Chillerón MJ, González-Chordá VM, López-Peña N, Cervera-Gasch Á, SuárezAlcázar MP, Mena-Tudela D (2019). Burnout syndrome in nursing students: An observational study. Nurse Educ Today, 76, 38-43. DOI: 10.1016/j.nedt.2019.01.014

Zong X, Zhang L, Yao M (2017). Parental Involvement and Chinese Elementary Students' Achievement Goals: The Moderating Role of Parenting Style. Educational Studies 44 (3), 341-356. DOI: 10.1080/03055698.2017.1373634 